\title{
Study of the Role of Antioxidant (Vitamin C) on Modulation Toxicity of Chronic Use of Monosodium Glutamate in Liver of Albino Rats
}

\author{
Hosam Eldin Hussein Osman', Said Said Elshama², Ayman El-Meghawry El- \\ Kenawy3
}

\footnotetext{
${ }^{1}$ Anatomy Department, Faculty of Medicine, Taif University (KSA) and Al-Azhar University (Egypt)

${ }^{2}$ Forensic Medicine and Clinical Toxicology Department, Faculty of Medicine, Taif University and Suez Canal University (Egypt)

${ }^{3}$ Pathology Department, Faculty of Medicine, Taif University and Menoufiya University (Egypt)
}

\section{Corresponding author}

Said S. Elshama: saidelshama@yahoo.com

All rights reserved.

\begin{abstract}
Introduction: Monosodium glutamate (MSG) is now used in many foodstuffs as a food additive and flavour enhancer. Although it has classified as safe food ingredient, the use of MSG remains controversial. MSG is a slow excitotoxin food additive which can cause generation of numerous amounts of free radicals which affects many organs such as liver. Vitamin $\mathrm{C}$ is an antioxidant and inhibits chemical carcinogenesis by protecting the body against oxidative stress. Aim of the study: Study role of antioxidant (vitamin C) on modulation biochemical, histological, histochemical and ultrastructural changes of liver caused by chronic use of MSG. Materials and Methods: Sixty adult albino rats divided into equal three groups, first group (control) received $1 \mathrm{ml}$ of saline daily for three months, Second group received MSG $6 \mathrm{mg} / \mathrm{g} / \mathrm{BW} / \mathrm{day}$ for three months, third group received MSG $6 \mathrm{mg} / \mathrm{g} / \mathrm{BW} /$ day and vitamin C $500 \mathrm{mg} / \mathrm{kg} / \mathrm{b} . \mathrm{w} /$ day, orally and for three months. Biochemical changes were investigated by the liver function tests. Assessment of histopathological changes of liver was done by using light microscope, transmission electron microscope, histochemical studies and immuohistochemical studies. Results: After chronic use of MSG, light microscope and transmission electron microscope examination revealed severe histopathological changes such as hepatic architecture destruction and dilatations of the central veins with statistical significant increase of liver enzymes. Histochemical studies revealed severe reduction of carbohydrates and proteins; pyknotic nucleus, vacuolated cytoplasm, swollen mitochondria and vesiculated rough endoplasmic reticulum with significant positive stained nuclei with ki-67 and p53. Administration of Vitamin C with MSG led to significant improvement of biochemical and pathological changes of liver. Conclusions: Chronic use of MSG caused hepatotoxicty of rats which is improved by administration of Vitamin C with it.
\end{abstract}

Keywords Monosodium glutamate, Vitamin C, Liver

\section{Introduction}

$\mathrm{M}$ onosodium glutamate (MSG) is used commercially as a food additive and is commonly marketed as a flavour enhancer. It is now used by most fast-food chains and in many foodstuffs, in particular, processed foods (Leung and Foster, 2003).
Trade names of monosodium glutamate include Ajinomoto, Vetsin, Ac'cent and Tasting Powder (Beyreuther et al., 2007). It was once made predominantly from wheat gluten, but is now made mostly from the fermentation of carbohydrates with a nitrogen source, using bacterial or yeast species from 
genera such as Brevibacterium, Arthrobacter, Microbacterium, Micrococcus and Corynebacterium (Willams and Woessner, 2009) .

MSG is a slow poison which hides behind dozens of names, such as natural flavouring and yeast extract. It is not a nutrient, vitamin, or mineral and has no health benefits. The part of MSG that negatively affects the human body is the "glutamate", not the sodium. The breakdown of MSG typically consists of $78 \%$ glutamate, $12 \%$ sodium, and about $10 \%$ water (Stevenson, 2000).

Any glutamate added to a processed food is not considered naturally occurring. Natural glutamate in plants and animals is known as L-glutamic acid. Our normal digestive process slowly breaks down this natural or "bound" glutamic acid and it is then delivered to glutamate receptors in our body and brain. Broken down this way, it is harmless. In a factory, however, the bound glutamic acid in certain foods (corn, molasses, wheat) is broken down or made "free" by various processes (hydrolyzed, autolyzed, modified or fermented with strong chemicals, bacteria, or enzymes) and refined to a white crystal that resembles sugar (Hazar et al., 2008).

Although the Food and Drug Administration (FDA) has classified MSG as a food ingredient that's "generally recognized as safe", the use of MSG remains controversial. For this reason, when MSG is added to food, the FDA requires that it be listed on the label (Ortiz et al., 2006).

MSG is toxic to humans and that over $25 \%$ of the population suffer adverse reactions from MSG7-36. In general, the natural glutamic acid found in food does not cause problems, but the synthetic free glutamic acid formed during industrial processing is a toxin. In addition, when MSG is formed using hydrochloric acid the final product includes carcinogens (Geha et al., 1998).

MSG is excitotoxin food additives. It is also known that excitotoxins themselves can cause the generation of numerous amounts of free radicals and that during the process of lipid peroxidation (oxidation of membrane fats) a substance is produced called 4hydroxynonenal. This chemical inhibits the glutamate transporter, thus allowing glutamate to accumulate in the brain. Excitotoxins destroy neurons partly by stimulating the generation of large numbers of free radicals. Recently, it has been shown that this occurs not only within the brain, but also within other tissues and organs as well (liver and red blood cells) (Freeman, 2006).

Effects of excitotoxin food additives generally are not dramatic. Some individuals may be especially sensitive and develop severe symptoms and even sudden death from cardiac irritability, but in most instances the effects are subtle and develop over a long period of time (Kondoh and Torii, 2008).

The liver is the second largest organ in the human body after the lung and it is one of the five vital organs. The liver conducts several hundreds of functions every second; it metabolizes nutrients and substances, helps with food digestion and cleans the blood. It also stores many vitamins and minerals. The condition of the liver is often ignored until something is discovered to be wrong with the liver. The most common "condition" to affect the liver is toxicity, as defined in the Taber's Medical Dictionary as "being poisoned" (Collison et al., 2009). Rat liver and rat tissues metabolize glutamate by oxidative deamination (or transamination to oxaloacetic or pyruvic acid via alpha-ketoglutarate to succinate (Beyreuther et al., 2007).

Some studies revealed that during intestinal absorption, a large amount of glutamic acid is transaminated and consequently alanine levels in portal blood are elevated. If large amounts of glutamate are ingested, portal glutamate levels will increase, this elevation results in an increase hepatic metabolism of glutamate, leading to release of glucose, lactate, glutamine, and other amino acids, into systemic circulation (Eweka et al., 2011). Another studies found that MSG caused an enlargement of the liver and an increase of serum albumin and decrease in serum globulin (Diniz et al., 2004).

Vitamin C (L-ascorbic acid) is an essential nutrient for humans and certain other animal species. In living organisms, ascorbate acts as an antioxidant by protecting the body against oxidative stress. It is a powerful reducing agent capable of rapidly scavenging a number of reactive oxygen species (ROS). Ascorbic acid is a well known for its antioxidant activity, acting as a reducing agent to reverse oxidation in liquids. When there are more free radicals (reactive oxygen species"ROS") in the human body than antioxidants, the condition is called oxidative stress. It prevents oxidative damage to the important biological macromolecules, such as DNA, proteins and lipids. Some investigators reported that antioxidants inhibit chemical carcinogenesis when the antioxidants are administered either prior or with carcinogen (Padayatty et al., 2003).

Vitamin $\mathrm{C}$ exerts protective role against acute ultraviolet B-rays (Sunburn cell formation), organophosphorous pesticides and could reduce aflatoxin induced liver cancer (Meves et al., 2002). Moreover vitamin $\mathrm{C}$ abolishes chromosome damage resulted from the effect of toxic substances and help to protect the body against pollutants. Because vitamin $\mathrm{C}$ is a biological reducing agent, it is also linked to preventive of degenerative diseases such as cataracts, certain cancer and cardiovascular disease (Barros et al., 2004).

Increased vitamin $\mathrm{C}$ intake could possibly reduce and prevent nephrotoxic effect. It assists in the prevention of blood clotting and bruising. It strengthens the walls of the capillaries and it is also needed for healthy gum. Vitamin $\mathrm{C}$ helps to reduce cholesterol levels, high blood pressure and preventing atherosclerosis. It protects susceptible cells from genotoxicity associated with antiestrogen metabolite-4- 
hydroxyl tamoxifen (4-OH tom) and inhibit DNA adduct induced by tamoxifen (Pavlovic et al., 2009).

There were many previous studies about modulation of MSG toxicity by other materials. Oscar et al., (2006) studied positive effect of vitamin E on monosodium glutamate induced oxidative stress in rats. Hazar et al., (2008) showed hepatoprotective effect of Nacetyl cysteine and carotene on monosodium glutamate induced toxicity. Pavlovic et al., (2009) used the ascorbic acid to modulate monosodium glutamate induced cytotoxicity in rat thymus.

The present study aims to evaluate role of antioxidant (vitamin C) on modulation biochemical histological, histochemical and ultrastructural changes of liver caused by chronic use of monosodium glutamate.

\section{Material and methods}

Sixty adult albino rats, 8-10 weeks of age, weighing 120 $140 \mathrm{~g}$. They were maintained on a standard laboratory conditions. Rats were divided equally into three groups. First group "control" $(\mathrm{n}=20)$ received $1 \mathrm{ml}$ of physiological saline $(0.9 \%)$ daily by oral route "orogastric tube" for three months. Second group $(n=20)$ received monosodium glutamate $(6 \mathrm{mg} / \mathrm{gm}$ of body weight/day, dissolved in $1 \mathrm{ml}$ of physiological saline " $0.9 \%$ ", orally "orogastric tube") for three months also. Third group received monosodium glutamate $(6 \mathrm{mg} / \mathrm{gm}$ of body weight/day, dissolved in $1 \mathrm{ml}$ of physiological saline " $0.9 \%$ ") and vitamin C (500 mg/kg of body weight of /day, orally "orogastric tube") for three months .

Monosodium glutamate was obtained from Morgan Company for Chemical Industry (Tenth of Ramadan City- Egypt). Vitamin C (L- ascorbic acid) was obtained from Egyptian pharmaceutical industries company.

Blood samples were collected from hearts of rats of all groups on the last day (the ninety day). These samples centrifuged at 3000 rounds for 10 minutes for separation of the serum. This serum was analyzed for the following liver functions tests:

\section{1- Aspartate Aminotransferase "AST"}

AST is increased in the serum after hepatic tissue necrosis because most of the circulating AST activity is derived from the hepatocytes isoenzyme which presents in the liver cell (Crawford, 2006). Assay of AST was performed by mixing the serum to buffered solution of L-aspartic acid and 2-ketoglutarate and then incubated for one hour at $37{ }^{\circ} \mathrm{C}$. After incubation, $1 \mathrm{~mm}$ of DNPH and $0.4 \mathrm{~m}$ of $\mathrm{NaOH}$ was added (Chatterjee, 1993).

\section{2- Alanine Aminotransferase "ALT"}

ALT is localized to hepatocytes alone with high specificity. It is increased after hepatic cellular injury (Sherlock, 1997). Assay of ALT was performed by mixing the serum to buffered solution of DL- alanine and 2- ketoglutarate, and then incubated for thirty minutes at $37^{\circ} \mathrm{C}$. After incubation, $1 \mathrm{~mm}$ of DNPH and $0.4 \mathrm{~m}$ of $\mathrm{NaOH}$ was added (Daniel and Marshall, 1999).

\section{3- Alkaline Phosphatase "ALP"}

Elevation of serum alkaline phosphatase is resulted from any disease which will affect hepatocyte secretion because it is represented near the canalicular membrane of the hepatocyte (Pincus and Abraham, 2006). Assay of ALP was performed by using pnitrophenol phosphate as substrate, in al alkaline buffer with fresh unhemolysed serum for $45 \mathrm{~min}$ at $12^{\circ} \mathrm{C}$ (Daniel and Marshall, 1999).

\section{Histological studies using light microscope}

All animals were sacrificed after three months. Abdominal viscera were exposed by midline incision. The liver from the three groups were rapidly excised, cut into small pieces and dropped in formalin in which they were kept for appropriate time. After fixation, they were subjected to the normal procedure for paraffin embedding. Sections were cut at the thickness of 5 microns and stained with Haematoxyline-Eosin and Periodic acid Schiff reaction (PAS) and then tissue sections were investigated using light microscope (Drury and Wallington, 1980).

\section{Histological studies using transmission electron microscope}

Small pieces $(1 \mathrm{~mm})$ of treated tissues were cut and fixed in 3\% glutaraldehyde (pH 7.4) in phosphate buffer and post fixed in $2 \%$ osmium tetroxide in phosphate buffer. Following fixation, tissues were dehydrated at increasing concentrations of ethanol. They were then embedded in araldite resin. Ultrathin sections were cut using an ultratome. Ultrathin sections were stained by uranyl acetate saturated in $70 \%$ ethanol and lead citrate. Tissue sections were evaluated using a JEOL transmission electron microscope JEM-1200. Ex, Japan (Bancroft and Gamble, 2002).

\section{Immunohistochemical studies}

Immunohistochemistry is a localization of antigens or proteins in tissue sections by the use of labeled antibodies as specific reagents through antigen-antibody interactions that are visualized by a marker such as fluorescent dye or enzyme. Immunohistochemical studies was done and staining was performed using Immunohistochemistry stainer (DAKO Auto stainer Link48 _ Serial NO: As1217D0904) a standard avidinbiotin peroxidase complex (ABC) method (Heras et al., 1995).

\section{The Ki-67}

Antigen Ki-67 is a nuclear protein which is necessary for cellular proliferation and associated with ribosomal RNA transcription. Inactivation of this antigen leads to inhibition of ribosomal RNA formation. Positive expression of this antigen (Ki-67) indicates to the 
increasing of cellular proliferation (Rahmanzadeh et al., 2007).

\section{The p53}

It is a tumor suppressor protein in the human and is encoded by the TP53 gene. It has an important role in apoptosis (cell death), genomic stability, and inhibition of angiogenesis. Positive expression of this protein (p53) indicates to tumor suppressor gene mutation (Kametaka et al., 2002).

\section{The procedure}

The Ki-67 and p53 proteins expression were examined using Ki-67 and p53 antibodies with dilution 1: 200 and $3 \mu \mathrm{g} / \mathrm{ml}$ for 30 minutes at room temperature respectively (Lab Vision Corporation, USA). With reference to the manufacturer's specifications, these antibodies reacts broadly with all known Ki-67 and P53 variants of human, rat and mouse origin by immunohistochemistry. Each set of experiments included a positive control and ensured the reproducibility of the staining process. A negative control, in which the primary antibody was omitted, was also included in each set of experiments. The positive localization result was nuclear staining in two markers (Ki-67and P53). Each section was counted manually at high power (X400) after identifying at low power (x100) the representative areas with the highest concentration of stained cells according to the recommendation of (Andrew et al., 2010). About 1000 cells/slide were counted in each of five microscopic fields from welllabeled areas to determine the average of Ki-67 and P53 labeling index (LI). LI was expressed as number of labeled cells (positive for stain) as a percentage of the total number of cells counted in each specimen. All identifiable staining was regarded as positive.

\section{Statistical analysis}

Results of this study were analyzed by using non parametric test (Mann Whitney U test), Chi-Square test and independent sample T-test for comparisons.

\section{Ethical considerations}

The most appropriate animal species was chosen for this research. Promotion of a high standard of care and animal well-being at all times was done. Appropriate sample size was calculated by using the fewest number of animals to obtain statistically valid results. Surgical or other painful procedures were performed with appropriate sedation to avoid distress and pain. Our standards of animal care and administration met those required by applicable international laws and regulations.

\section{Results}

\section{Biochemical changes}

Table (1) shows mean + SD values of liver enzymes of rats (ALT, AST, and ALP). Mean +SD values of ALT were $11.25 \pm 4.30$ in control group which received saline $0.9 \%, 48.9 \pm 14.3$ in second group which received monosodium glutamate dissolved in saline $0.9 \%$ and $24.3 \pm 2.20$ in third group which received monosodium glutamate dissolved in saline $0.9 \%$ and vitamin C. Mean + SD values of AST were $31.66+3.70$ in control group which received saline $0.9 \%, 53.25 \pm 9.3$ in second group which received monosodium glutamate dissolved in saline $0.9 \%$ and $36.13+1.91$ in third group which received monosodium glutamate dissolved in saline $0.9 \%$ and vitamin C. Mean \pm SD values of ALP were $88.77 \pm 6.4$ control group which received saline $0.9 \%, 132.35 \pm 10.2$ in second group which received monosodium glutamate dissolved in saline $0.9 \%$ and $92.12 \pm 3.3$ in third group which received monosodium glutamate dissolved in saline $0.9 \%$ and vitamin $\mathrm{C}$.

The previous data of table (1) showed that administration of MSG alone in the second group produced a statistical significant elevation of liver enzymes values when compared with the control group. Administration of vitamin C with MSG in third group leads to statistical significant difference of liver enzymes values when compared with the second group.

\section{Macroscopic appearance}

Liver rats of second and third groups were pale color with congestion and edema. Hepatic borders were lost. When the liver was cut, there were signs of edema and congestion.

\section{Histopathological findings by light microscope}

Examination of the liver control rats showed normal hepatic structure (Fig.1\&2). But liver sections of second group rats showed loss of its characteristic architecture compared with the control group, the cytoplasm of the hepatocytes was characterized by coarse, pink, increased number of vacuoles and inflammatory cellular infiltration was abundant around the central vein with small fragmented pyknotic nuclei (Fig. 3), With more dilatation of central vein and blood sinusoids with degenerated vacuolated cytoplasm and multiple pyknotic nuclei (Fig.4). Liver sections of third group rats showed hypertrophy of hepatocytes and mild hypertrophy of kupffer cells with marked diminution of hydropic degeneration (Fig.5\&6).

\section{Histochemical results}

\section{1- Glycogen content}

Control liver sections stained with periodic acid schiff's (PAS) showed mucopolysaccharide granules in the cytoplasm of hepatocytes, but the peripheral zonal cells showed higher mucopolysaccharide content than the central zonal cells (Fig.7). Liver sections of second group showed severe reduction of total amount of PAS positive material (Fig.8). Liver sections of third group showed mild reduction of PAS positive material but not reached to control group (Fig.9). 


\section{2- Collagen content}

Control liver sections showed normal distribution of collagen and small amount of wavy fibrils (Fig.10). Collagen wavy fibrils either singly or fused together in dense bundles was observed in the second group (Fig.11). Liver sections of third group showed improvement in collagen deposition and connective tissue fibers as compared to liver of second group rats (Fig. 12).

\section{Histopathological findings by transmission electron microscope}

The ultrastructure of liver control rats showed that the hepatocytes were separated by blood sinusoid which lined by endothelial cells. The cytoplasm has a finely granular appearance due to the presence of numerous free glycogen granules. The mitochondria were numerous, usually round to oval in shape. The nuclei of the hepatocytes were oval or rounded with nucleoplasm consisting of a finely granular component, thin peripheral heterochromatin and euchromatin condensation. The sinusoidal lumina were lined by flat endothelial cells or their extensions which were separated from the adjacent hepatocytes by the subendothelial space or space of Disse (Fig.13\&14).

The hepatocytes of liver of second group showed vacuolated cytoplasm (V), swollen mitochondria (M) and vesiculated rough endoplasmic reticulum (VER) with picknotic nuclei (Fig.15); dense collection of inflammatory cells including macrophages was observed in the cytoplasm (M) and the nuclear membrane is corrugated (Fig.16). Vacuolation (V) and dilatation of endoplasmic reticulum with no obvious ribosomes (RER) and atrophied mitochondria with ill- differentiated cisternae were noted (Fig.17).

The ultrastructural changes of the hepatocytes of liver of third group showed improvement in the form of diminution of cytoplasmic dissolution, well-defined nucleolus and nuclear envelope. Moreover, there were normal-shaped rough endoplasmic reticulum, but mitochondria were still dilated (Fig.18).

Table (2) shows P Values of histopathlogical results comparing between different groups using ChiSquare Test. P value of histopathological examination by light microscope of the second group which received MSG in comparison with first group which received normal saline (control) was 0.02. $\mathrm{P}$ value of histopathological examination by electron microscope of the second group which received MSG in comparison with the first group which received normal saline (control) was $<0.01$. $\mathrm{P}$ value of histopathological examination by light microscope of the third group which received MSG with vitamin $\mathrm{C}$ in comparison with the first group which received normal saline (control) was 0.01 . $\mathrm{P}$ value of histopathological examination by electron microscope of the third group which received MSG with vitamin $\mathrm{C}$ in comparison with the first group which received normal saline (control) was 0.02 . P value of histopathological examination by light microscope of the third group which received MSG with vitamin C in comparison with the second group which received MSG was 0.04 . $\mathrm{P}$ value of histopathological examination by electron microscope of the third group which received MSG with vitamin $\mathrm{C}$ in comparison with the second group which received MSG was $<0.01$.

The previous data of table (2) showed statistically significant difference of histopathological results using the light and electron microscope in second group that received MSG alone in comparison with the control group. There was statistically significant difference of histopathological results using the light and electron microscope in third group which received vitamin $\mathrm{C}$ and $\mathrm{MSG}$ in comparison with the second group which received MSG alone. There was also statistically significant difference of histopathological results using the light and electron microscope in third group which received vitamin C and MSG in comparison with the control group.

\section{Immunohistochemical results}

The immunohistochemical study showed great differences in positivity of staining among different groups. The liver sections of control group rats which received saline and third group rats which received MSG and Vitamin C stained with Ki-67 showed slightly faint staining nuclei indicating the mild cell division of some hepatocytes (Fig.19). However, there was a strong immunoreactivity in liver section of second group rats which received MSG (Fig.20).

Table (3) explains the changes in liver Ki-67 and p53 indices. Rats of second group which received MSG were highly significant, while rats of third group which received MSG and vitamin $\mathrm{C}$ were high significant increase in compared with control rats and high significant when compared with second group (Fig.21). On the other hand, we used P53 as the Pro-apoptotic marker, where the liver sections of control and second groups were significant expression of p53. However, the liver sections of third group showed very weak positive stained nuclei (less than $10 \%$ of total cells) (Fig. 22, 23, 24).

The previous data of table (3) showed that administration of MSG alone in the second group produced a statistical significant difference of hepatic Ki67 and P53 values when compared with the control group. Administration of vitamin C with MSG in third group leads to statistical significant difference of hepatic Ki-67 and P53 values when compared with the second group which received MSG alone. 
Table (1): Effect of chronic use of monosodium glutamate on mean + SD of liver enzymes of rats.

\begin{tabular}{|l|c|c|c|}
\hline Enzymes & $\begin{array}{c}\text { ALT } \\
\text { (IU/L) }\end{array}$ & $\begin{array}{c}\text { AST } \\
\text { (IU/L) }\end{array}$ & $\begin{array}{c}\text { ALP } \\
\text { (IU/L) }\end{array}$ \\
\hline Group 1 & $11.25+4.30$ & $31.66+3.70$ & $88.77 \pm 6.4$ \\
\hline Group 2 & $48.9 \pm 14.3^{*}$ & $53.25+9.3^{*}$ & $132.35 \pm 10.2^{*}$ \\
\hline Group 3 & $24.3 \pm 2.20^{* *}$ & $36.13 \pm 1.91^{* *}$ & $92.12 \pm 3.3^{* *}$ \\
\hline
\end{tabular}

$A L T=$ alanine aminotransferase; $A S T=$ aspartate aminotransferase; $A L P=$ alkaline phosphatase.

Group 1= Control (received saline 0.9\%); Group 2= received monosodium glutamate dissolved in saline 0.9\%; Group 3= received monosodium glutamate dissolved in saline $0.9 \%$ and vitamin $C$.

${ }^{*}=p<0.05$ (significant difference in comparison with control group); ${ }^{* *}=p<0.05$ (significant difference in comparison with second group). Statistical analysis was performed by non - parametric test (Mann Whitney U test).

Table (2) P values of histopathlogical results comparison between different groups using chi-square test.

\begin{tabular}{|l|c|c|}
\hline Group Pathological exam & Light Microscope & Electron Microscope \\
\hline $\mathrm{G}_{2} \mathrm{Vs} \mathrm{G}_{1}{ }^{* * *}$ & 0.02 & $<0.01$ \\
\hline $\mathrm{G}_{3} \mathrm{Vs} \mathrm{G}_{1}{ }^{{ }^{* * *}}$ & 0.01 & 0.02 \\
\hline $\mathrm{G}_{3} \mathrm{Vs} \mathrm{G}_{2}{ }^{*}$ & 0.04 & $<0.01$ \\
\hline
\end{tabular}

$P<0.05$ is statistically significant.

"Comparison between $G_{2}$ (received MSG dissolved in saline 0.9\%) and $G_{1}$ (Control which received saline 0.9\%);

${ }^{* *}$ Comparison between $G_{3}$ (received $M S G$ dissolved in saline $0.9 \%$ and vitamin $C$ ) and $G_{1}$ (Control which received saline $0.9 \%$ ); ${ }^{* * *}$ Comparison between $G_{3}$ (received $M S G$ dissolved in saline $0.9 \%$ and vitamin $C$ ) and $G_{2}$ (received MSG dissolved in saline $0.9 \%)$.

Table (3): Comparison of hepatic Ki-67 and P53 indices among different groups.

\begin{tabular}{|l|c|c|c|c|c|c}
\hline \multirow{2}{*}{ Gntibody } & \multicolumn{2}{c|}{ Control } & \multicolumn{2}{c|}{ Second } & \multicolumn{2}{c}{ Third } \\
\cline { 2 - 7 } & Ki-67 & P53 & Ki-67 & P53 & Ki-67 & P53 \\
\hline$X^{-}$ & 9.832 & 4.210 & 81.734 & 38.841 & 7.351 & 5.232 \\
\hline SD & 5.811 & 0.913 & 11.981 & 8.221 & 5.132 & 1.231 \\
\hline SE & 0.771 & 0.240 & 3.701 & 2.732 & 0.577 & 0.133 \\
\hline T-test & - & 0.720 & 16.971 & 10.024 & 2.011 & 1.223 \\
\hline P value & - & - & $\leq 0.01$ & $\leq 0.006$ & $\leq 0.03$ & $\leq 0.001$ \\
\hline
\end{tabular}

Control group $=$ first group, which received saline 0.9\%; the second group received monosodium glutamate dissolved in saline $0.9 \%$; the third group received monosodium glutamate dissolved in saline $0.9 \%$ and vitamin $C$.

$X^{-}=$mean value; $S D=$ standard deviation; $S E=$ standard error

Statistical analysis was performed by t-test (non-parametric test); $P<0.05$ is statistically significant.

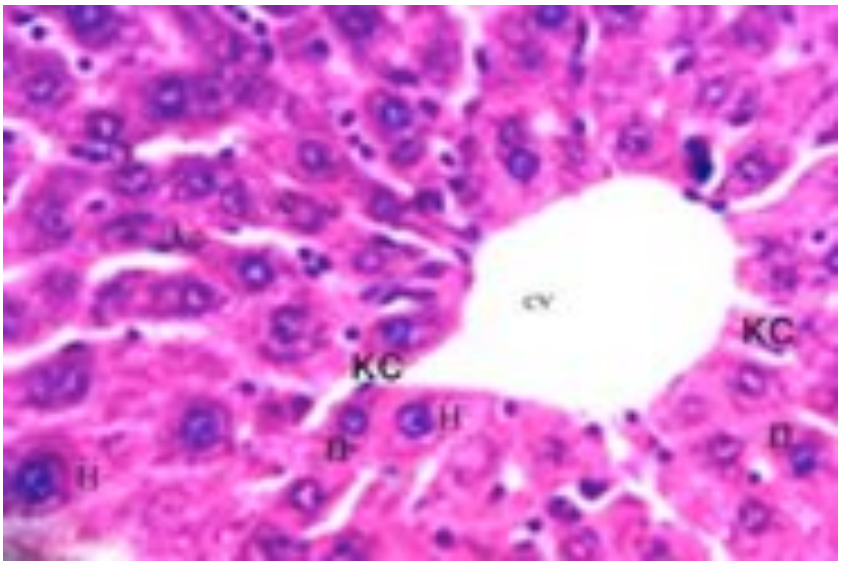

Fig. (1) Shows normal histological structure of liver of control rats. $\mathrm{H} \& \mathrm{E}(\mathrm{x} 400)$

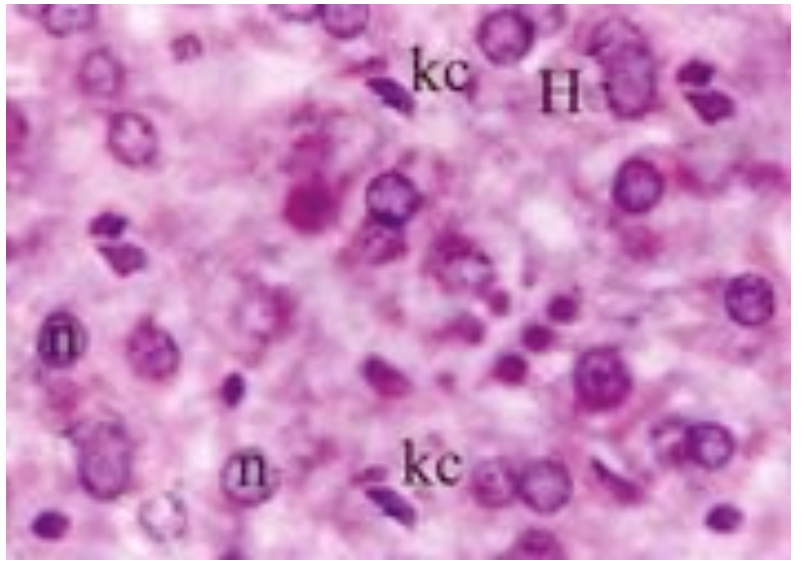

Fig. (2) Shows normal histological structure of liver of control rats. $H \& E$ (x1000) 


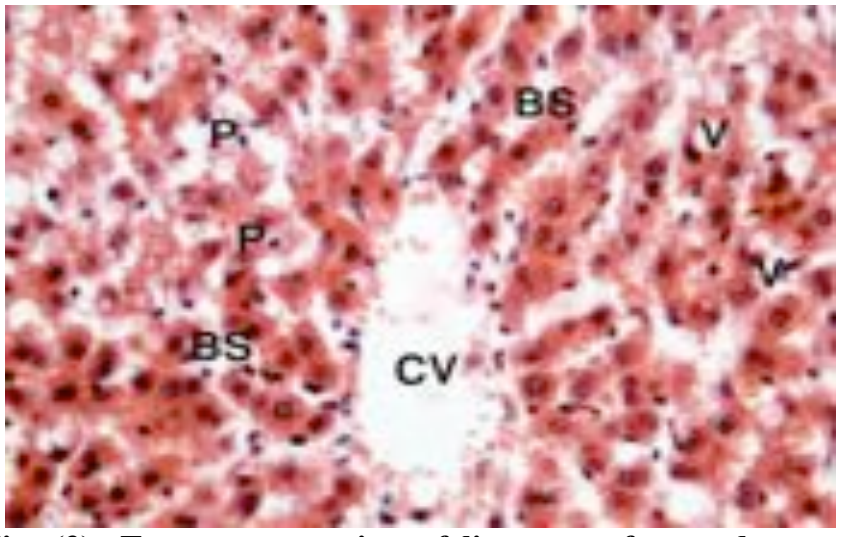

Fig. (3): Transverse section of liver rat of second group, shows dilatation of central vein $(\mathrm{CV})$ and blood sinusoids (BS) with degenerated vacuolated (V) cytoplasm with multiple pyknotic nuclei (P). H\&E (x400)

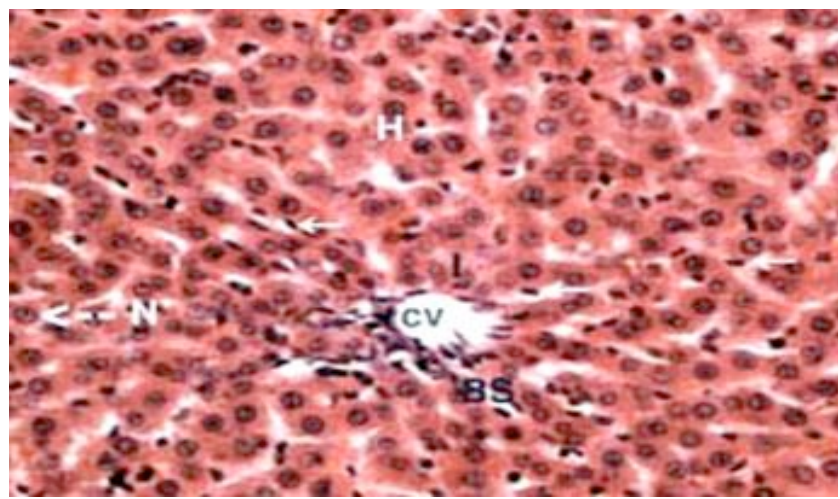

Fig. (5): Section of liver rat of third group shows normal central vein $(\mathrm{CV})$ and hepatocytes $(\mathrm{H})$ with normal nuclei (dotted arrow $\mathrm{N}$ ) and inflammatory cell infiltration (I) with increasing in Kupffer cell (arrow). H\&E (x400)

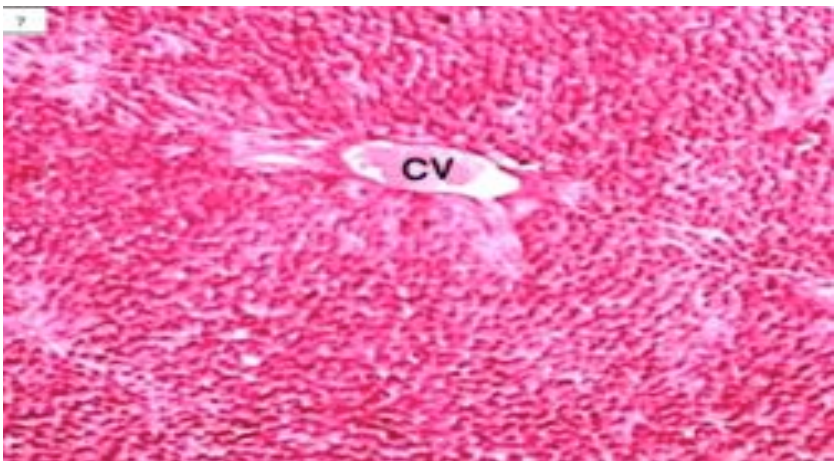

Fig. (7): Section of liver rat of control group shows PAS positive material in the cytoplasm of hepatocytes and normal central vein (CV), but nuclei has not any stains. PAS reaction (x200)
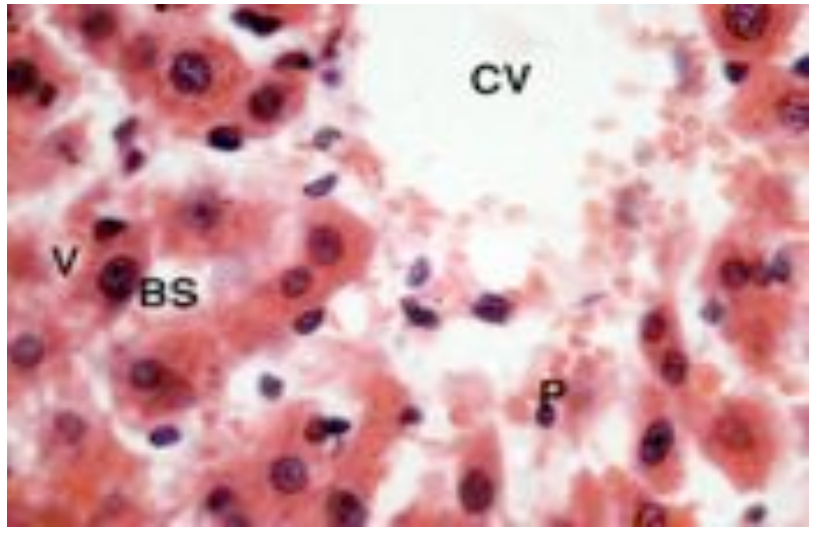

Fig. (4): Transverse section of liver rat of second group, shows dilatation of central vein (CV) and blood sinusoids (BS) with degenerated vacuolated (V) cytoplasm with multiple pyknotic nuclei (P). H\&E (x1000)

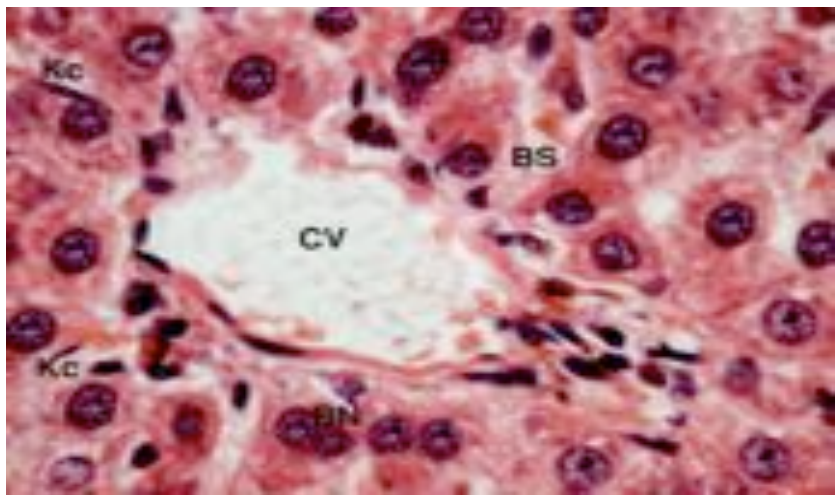

Fig. (6): Section of liver rat of third group shows hepatocytes with vacuolated cytoplasm (V) and separated by blood sinusoids (BS) which containing Kupffer cells (kc) and some binucleated (BN) cells. H\&E (x1000)

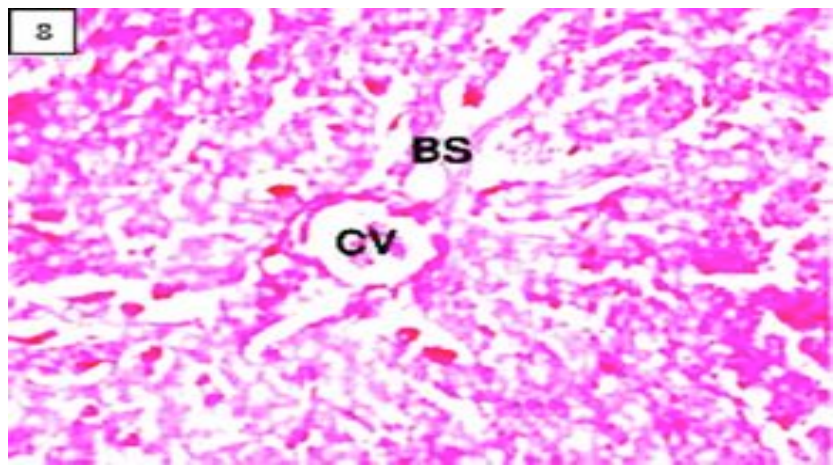

Fig. (8): Section of liver rat of second group shows decreased of PAS positive material in the cytoplasm (V) of hepatocytes, central vein (CV) blood sinusoids (BS). PAS reaction $(\mathrm{x} 400)$ 


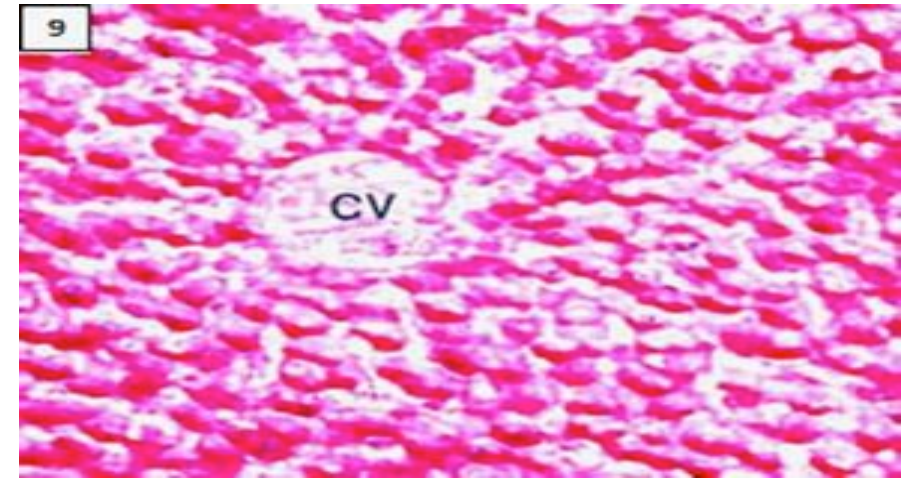

Fig. (9): Section of liver rat of third group shows improvement of PAS positive of cytoplasm of hepatocytes. PAS reaction $(x 400)$

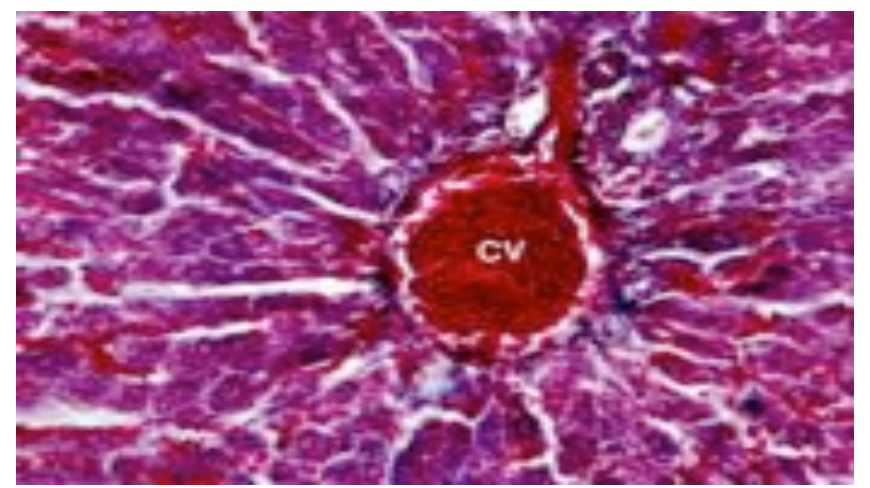

Fig. (11): Section of liver rat of second group shows increasing in collagen fiber especially around the central vein $(\mathrm{CV})$ and in between hepatocytes. Mallory stain $(x 400)$

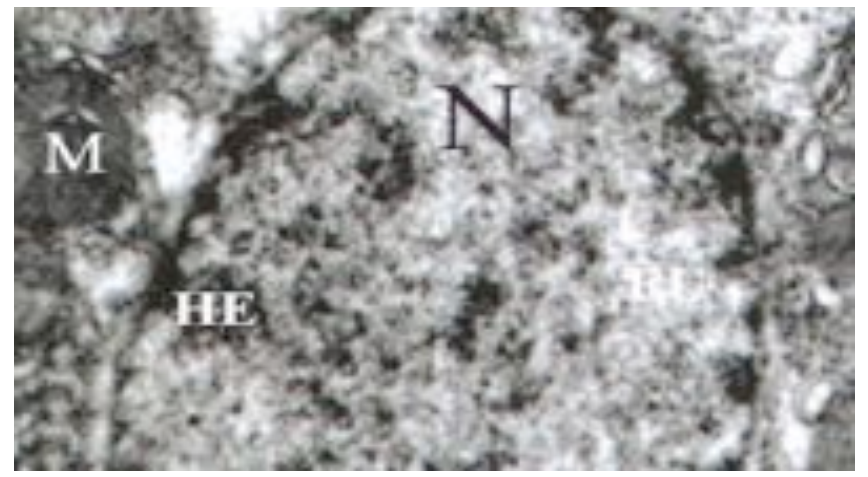

Fig. (13): Liver of control rats shows rounded nucleus (N) of hepatocytes with slightly condensed peripheral heterochromatin (HE) and euchromatin (EU), rounded mitochondria (M). Uranyl acetate \& lead citrate (x12000)

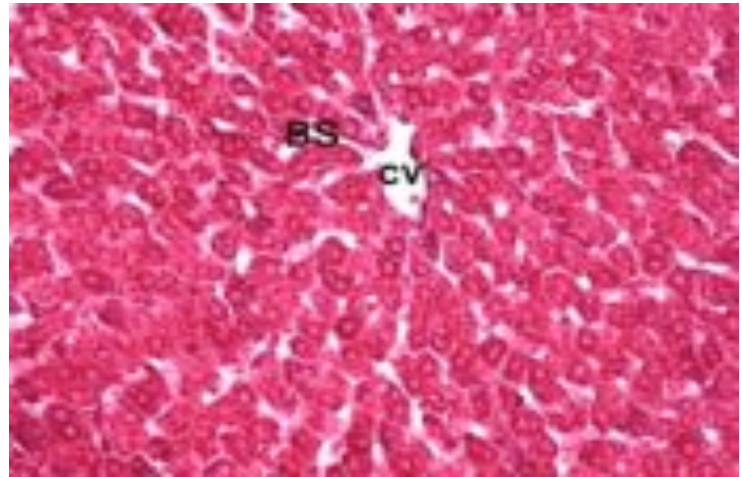

Fig. (10): Section of liver rat of control group shows normal distribution of collagen, with normal central vein (CV) and blood sinusoids (BS). Mallory stain (x200)

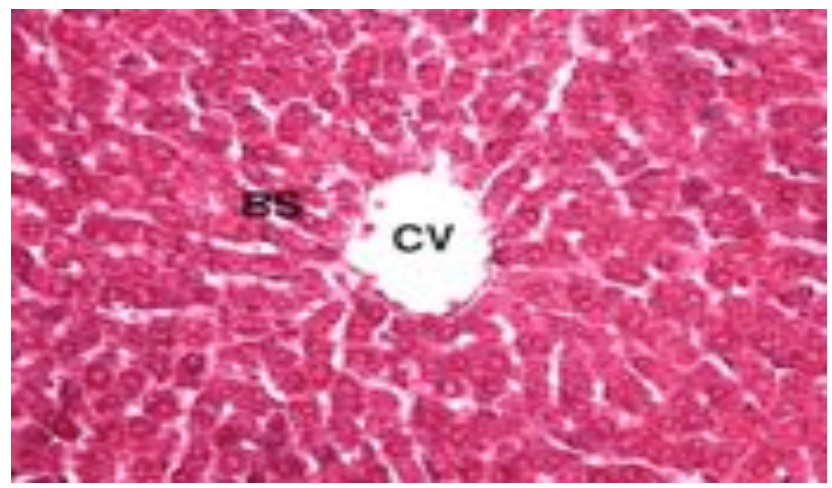

Fig. (12): Section of liver rat of third group shows normal distribution of collagen with normal central vein (CV) and blood sinusoids (BS). Mallory stain (x400)

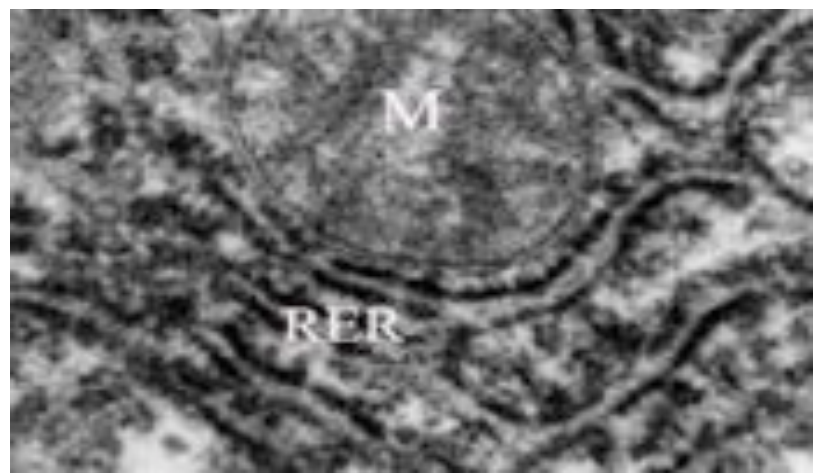

Fig. (14): Liver of control rats shows cytoplasm of hepatocytes which is crowded with organelles, particularly rough endoplasmic reticulum (RER) and normal mitochondria (M). Uranyl acetate \& lead citrate (x18000) 


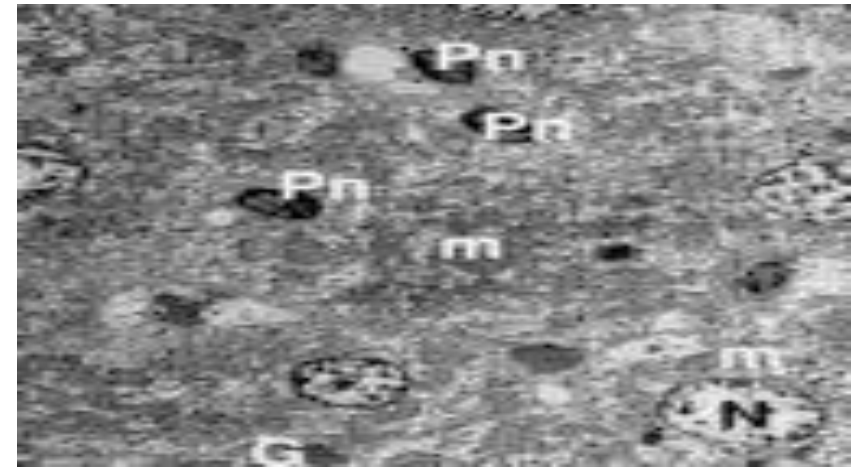

Fig. (15) : Liver of second group shows many hepatocytes which has signs of picknosis as irregular small nuclei (Pn) with many swollen mitochondria (m) and some cells appear normal nuclei $(\mathrm{N})$ and many glycogen granules (G). Uranyl acetate \& lead citrate (x2500)

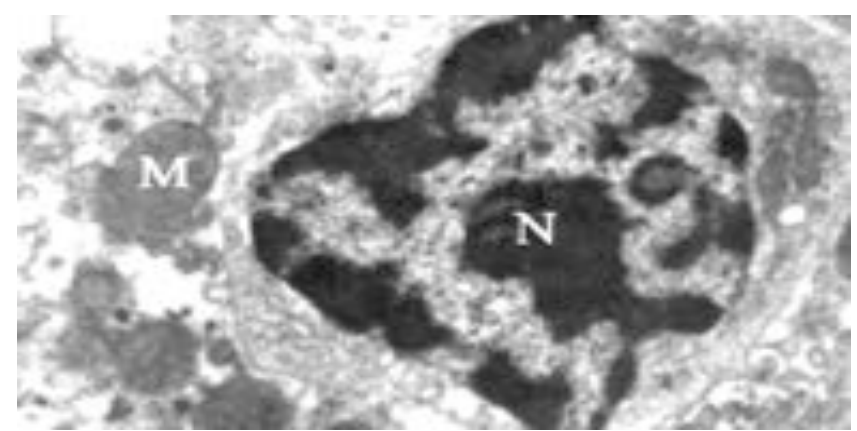

Fig. (17): Liver of second group shows hepatocytes with dense collection of inflammatory cells including macrophages $(M)$ and corrugated nuclear membrane $(N)$. Uranyl acetate \& lead citrate (x10000)

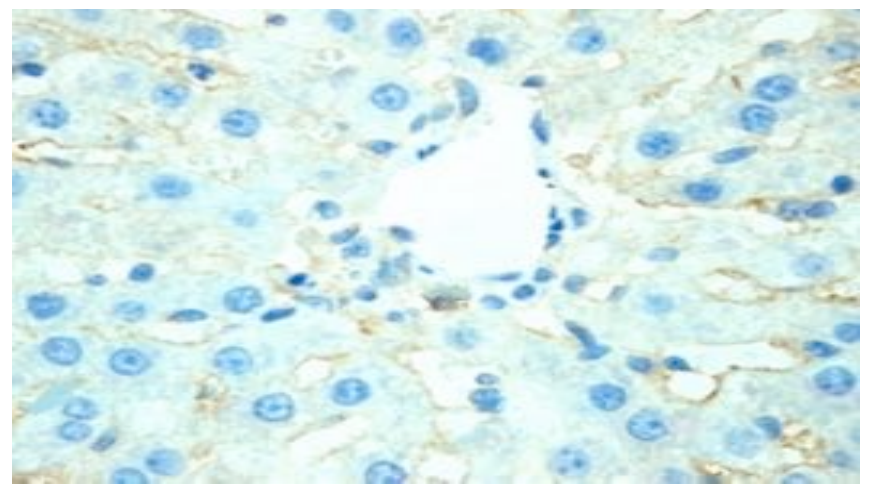

Fig. (19): Section of liver rat of control group shows negative staining of ki-67 in most of hepatocytes. Immunohistochemical staining (x400)

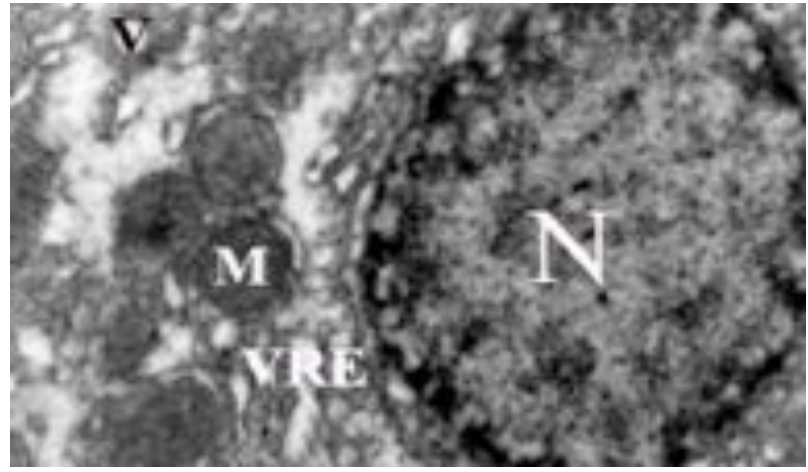

Fig. (16): Liver of second group shows hepatocytes with vaculated cytoplasm (V), swollen mitochondria (M) and vesiculated rough endoplasmic reticulum (VER) with picknotic nucleus (N). Uranyl acetate \& lead citrate (x8000)

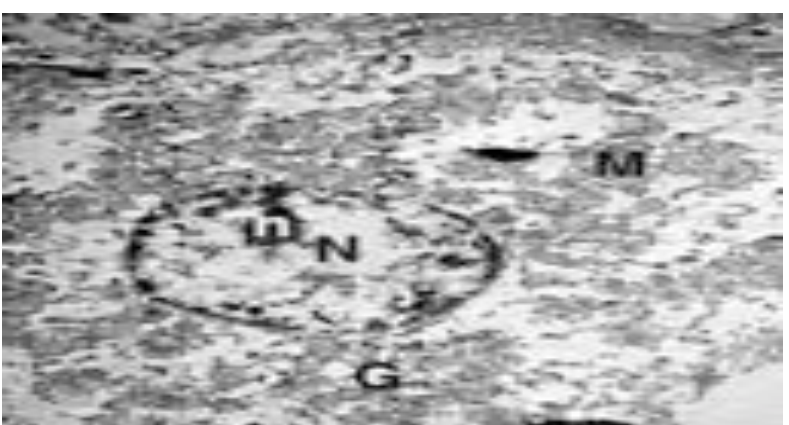

Fig. (18): Liver of third group shows hepatocytes with large rounded euchromatic nucleus $(\mathrm{N})$, well-defined nucleolus (n), nuclear envelope and dilated mitochondria (M). Uranyl acetate \& lead citrate $(\mathbf{x 6 0 0 0})$

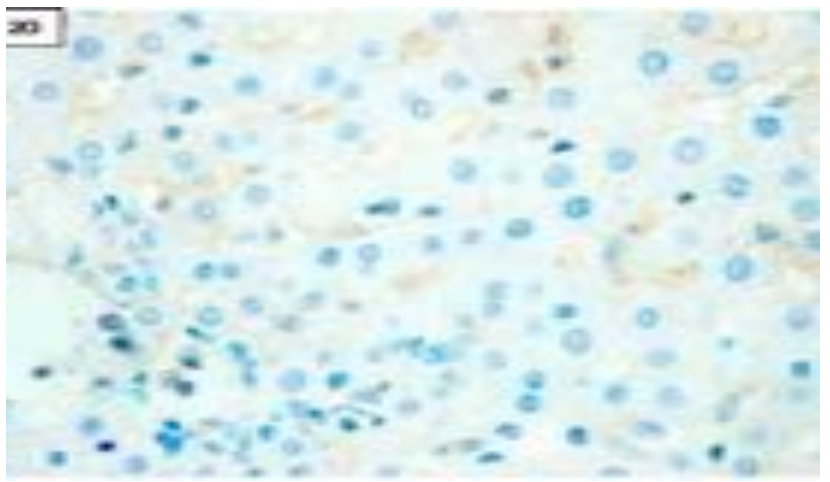

Fig. (20): Section of liver rat of control group shows negative staining of $\mathrm{p53}$ in most of hepatocytes. Immunohistochemical staining (x400) 


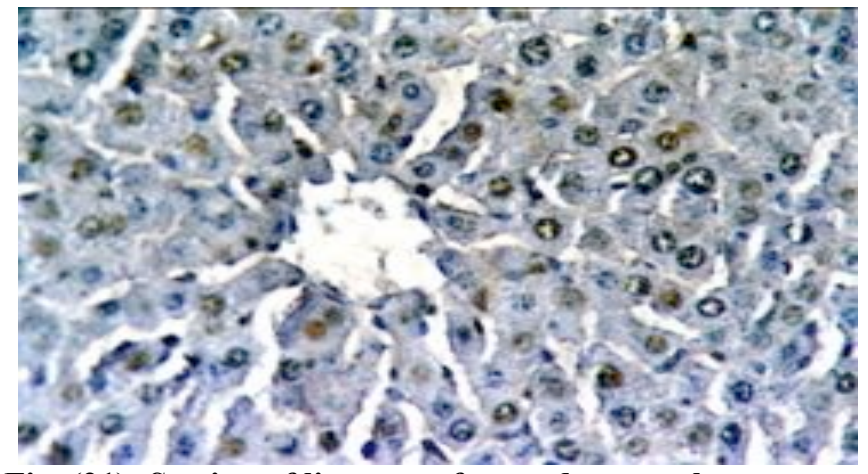

Fig. (21): Section of liver rat of second group shows strong staining of ki-67 in most of hepatocytes.

(Immunohistochemical staining X 400)

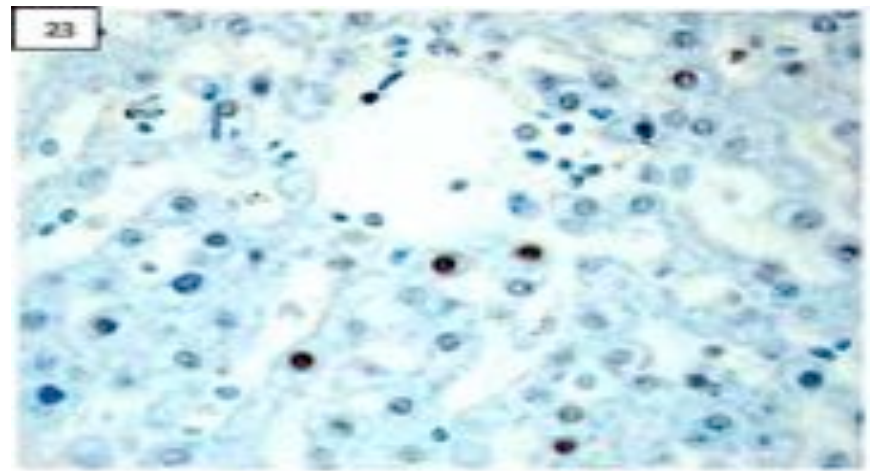

Fig. (23): Section of liver rat of third group shows faint immunoreactivity of ki-67 in nuclei of some hepatocytes. (Immunohistochemical staining $X$ 400)

\section{Discussion}

Monosodium glutamate (MSG) is one of the most common food additives, which is widely used as a popular flavoring agent in canned foods. This study showed hepatotoxicity of monosodium glutamate and the effect of antioxidants agents such as vitamin $\mathrm{C}$ for modulation this toxicity. We performed this study by three groups of adult albino rats. The first group was control and second group received MSG alone while third group received MSG and vitamin C. We used the liver function tests to evaluate biochemical changes. Assessment of histopathological changes of liver was done by using light microscope, transmission electron microscope, histochemical studies, and immunohistochemical studies.

The present study showed statistical significant increase of liver enzymes activities values such as ALT, AST and ALP in second group which received monosodium glutamate alone in comparison with control group. Sherlock (1997) referred that the use of liver function tests is associated with high specificity especially when more than one test is abnormal.

AST is present in both the mitochondria and hepatocytes while ALT is localized to hepatocytes alone. The hepatocytes and mitochondrial forms of AST are true isoenzymes and immunologically distinct. About $80 \%$ of AST activity in liver is contributed by the

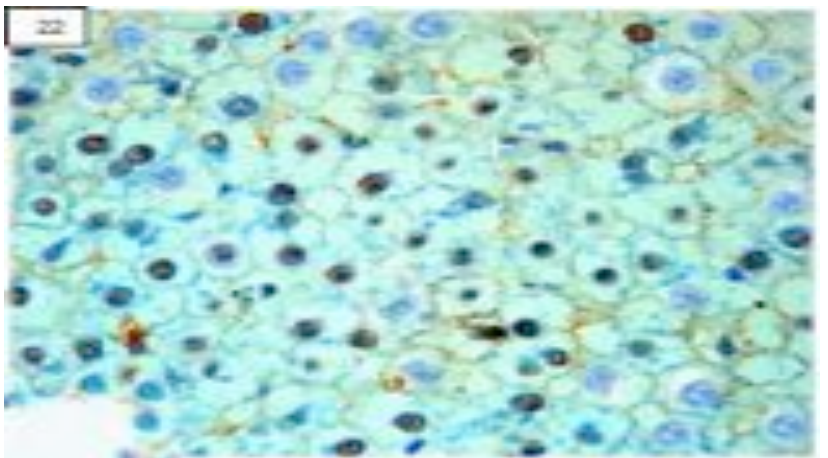

Fig. (22): Section of liver rat of second group shows strong staining of p53 in most of hepatocytes. ( Immunohistochemical staining $X$ 400)

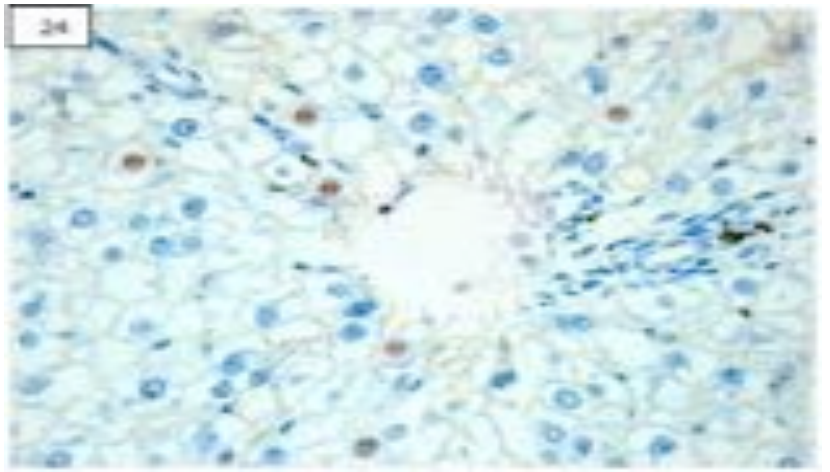

Fig. (24): Section of liver rat of third group shows faint immunoreactivity of p53 in nuclei of some hepatocytes. (Immunohistochemical staining $X$ 400)

mitochondrial isoenzyme, whereas most of the circulating AST activity is derived from the hepatocytes isoenzyme. Large increases in mitochondrial AST occur in serum after extensive tissue necrosis. Mitochondrial AST is increased in chronic liver disease. Serum alkaline phosphatase is a heterogeneous group of enzymes. Hepatic alkaline phosphatase is represented near the canalicular membrane of the hepatocyte. Accordingly, diseases that predominately affect hepatocyte secretion will be accompanied by elevations of alkaline phosphatase levels (Pincus and Abraham, 2006)

AST and ALT were increased as result of hepatic necrosis which induced by chronic administration of MSG. The current study showed cellular hypertrophy and degenerative changes in the liver cell of second group which received monosodium glutamate as result of the cytotoxic effect of MSG on the liver, and then the detoxification processes and other functions of the liver will be affected and this consistent with Eweka et al., (2011). In third group which received monosodium glutamate and vitamin C, Liver function tests values (ALT, AST and ALP) were statistical significant decreased in comparison with second group which received monosodium glutamate alone. Generation of reactive oxygen species (ROS) as result of oxidative stress of MSG toxic effect were depressed by antioxidant 
effect of vitamin $\mathrm{C}$ and this consistent with Oscar et al., (2006).

Sakr et al., (2003) suggested that toxic effect of MSG on the liver reflects on histopathological changes such as distortion of hepatocytes and dilatation of central vein of the liver. He reported that MSG administration increases the enzyme activity (ALT and AST) as result of heptocellular injury and cause increased ratio of AST-toALT by $56.59 \%$ indicating possible cirrhosis and this consistent with Beyreuther et al., (2007) who showed that rat liver metabolize glutamate by oxidative deamination and then if large amounts of glutamate are ingested, hepatic metabolism of glutamate and toxic metabolites will be increased.

Our results showed that MSG caused foci of degeneration in the form of pyknosis of hepatocytes nuclei and fibrosis. These results were in agreement with Egbuonu et al., (2009) who indicated that MSG induced hepatic necrosis and apoptosis, biliary proliferation, peribiliary fibrosis and degeneration of hepatocytes. Hazar et al., (2008) referred that oxidative stress which is responsible for the development of hepatic fibrosis and degeneration.

The present study showed that administration of MSG induced chronic inflammatory disease because of presence of inflammatory cells in the liver tissue and depletion of carbohydrates in the cytoplasm of hepatocytes. This consistent with Ortiz et al., (2006).

Our study showed that many ultrastructural abnormalities in the liver including lysosomes, endoplasmic reticulum, mitochondria and Golgi apparatus as result of cytotoxic effects of MSG. These results were in agreement with Iwase et al., (1998) who indicated also that Golgi apparatus is responsible for the packaging of hydrolytic enzymes involved in the formation of secretary products.

The current study showed that expansion of the mitochondrial intermembrane space and extension of the outer mitochondrial membrane leads to mitochondrial vacuolation and this consistent with Higgins et al., (2003) who referred also that vacuolation may be due to disturbance of ionic milieu of the cell with consequent retention of water and sodium leading to cellular swelling.

Our results showed that administration of vitamin $\mathrm{C}$ with administration of MSG leads to improvement in pathological changes of liver rats in comparison with group of rats which were administrated MSG alone. These results confirmed that protection effect of vitamin C against toxicity of MSG because of its antioxidant action and free radical scavenger. These results consistent with Barros et al., (2004) and Pavlovic et al., (2009) who added also that vitamin $\mathrm{C}$ reverses some pathological changes which were induced in thymus of rats as result of administration of MSG. Results of Freeman (2006) explained that MSG is excitotoxin which causes hepatic damage by stimulating the generation of large numbers of free radicals and then, modulation of hepatic toxicity of MSG was done by vitamin $\mathrm{C}$.

Scholzen and Gerdes (2000) indicated that Ki67 is a nuclear protein which is present in proliferating cells and expressed during late G1, S, M, and G2 phases of the cell cycle, while resting non-cycling cells (G0 phase) lacks of Ki-67 expression. Our results reported that high expression of ki-67 in the second group which was administered MSG only because it increases cell proliferation. In the third group which was administered vitamin $\mathrm{C}$ with $\mathrm{MSG}$, there was the low expression of ki67. So, vitamin $C$ reduces cellular proliferation induced by MSG administration because it has an ability to regulate the expression and activity of cell cycle-related proteins and this consistent with Hahm et al., (2007).

The p53 antibody reacts with only mutant p53 protein and the half live of wild type is short "about 30 minutes" (Limaye et al., 2003). Our study revealed that presence the p53 over expression in the second group which received MSG alone. But, this over expression was decrease in control group and the third group which received vitamin $\mathrm{C}$ with $\mathrm{MSG}$. So, our results confirmed that vitamin $\mathrm{C}$ may be caused alteration in tumor suppressor gene P53 by accumulate p53 protein because it inhibited this p53-induced Reactive Oxygen Species "ROS" generation and this consistent with Kim et al., (2008). Sung et al., (2011) indicated that another contrast fact which revealed that vitamin $\mathrm{C}$ induce P53 expression in colon cancer cell line.

Young and Woodside (2001) reported that Vitamin $\mathrm{C}$ is an antioxidant which removes free radicals products in the body and shows the ability to scavenge superoxide, hydrogen peroxide, and hydroxyl radicals. In the current study, the rats of control group and third group were similar in an immuohistochemical features, where the expression of both $\mathrm{Ki}-67$ and P53 antibodies were weak positive in the previous two groups indicating that decrease of proliferation in case $\mathrm{Ki}-67$ and mutation of P53 gene. So, our results revealed that the vitamin C has hepatoprotective effect on the parenchymal architecture of the liver against MSG because it caused significant decrease in proliferation cells and tumor suppressor genes mutation.

\section{Conclusion}

Chronic use of monosodium glutamate leads to hepatic toxicity which represents as biochemical, histopatholgical, and immunohistochemical changes in albino rats. Administration of Vitamin $\mathrm{C}$ as antioxidant agent with monosodium glutamate modulates hepatotoxicity induced by MSG.

\section{Recommendations}

Results of this study may be significant to animal but we need further researches in human to investigate our results. We suggest further studies with other parameters of liver assessment such as serum total protein, serum 
albumin, serum total bilirubin, prothrombin time and determination of oxidative stress parameters such as extent of lipid peroxidation, reduced glutathione tissue level "GSH", superoxide dismutase "SOD" and catalase activity to complete this work. According to this study, chronic use of MSG leads to toxic effect in the liver and administration of vitamin $\mathrm{C}$ with MSG has a protective action against its hepatic toxicity.

\section{References}

Andrew O E, Abieyuwa E and Ferdinard AE (2010): Histological studies of the effects of monosodium glutamate of the fallopian tubes of adult female Wistar rats. North American Journal of Medical Sciences, Volume 2: 146149.

Bancroft JD and Gamble M (2002): Theory and Practice Histological Techniques, 5th ed., Churchill Livingstone. New York, Edinburgh, and London, pp126 and 173-175.

Barros PS, Safatle AM and Queiroz I (2004): Blood and a aqueous humor antioxidants in cataractous poodles. Can. J. Opthalmol., 39 (1):19-24.

Beyreuther K, Biesalski HK and Fernstrom JD (2007): "Consensus meeting: monosodium glutamate an update". Eur. J. Clin. Nutr., 61 (3): 304-13.

Chatterjee TK (1993): Handbook of laboratory mice and rats . $1^{\text {st }}$ ed., K. Chatterjee Publisher, Calcutta, 38.

Collison KS, Maqbool Z and Saleh SM (2009): "Effect of dietary monosodium glutamate on trans fatinduced nonalcoholic fatty liver disease". Journal of Lipid Research 50 (8): 1521-1537.

Crawford JM (2006): Liver and biliary tract. Pathological basis of diseases. Robins and Cotran, $7^{\text {th }}$ ed., 77938.

Daniel SP and Marshall MK (1999) : Evaluation of the liver: laboratory tests. Schiff's diseases of the liver, 8th edn. USA; JB Lippincott publications, 205-239.

Diniz YS, Fernandes A, Campos KE et al., (2004): Toxicity of hypercaloric diet and monosodium glutamate: Oxidative stress and metabolic shifting in hepatic tissue. Food-and- chemical Toxicology,42:2, 313-319

Drury RA and Wallinggton EA (1980): Carlton Histological Technique $4^{\text {th }}$ Ed.Oxford Press, 6575.

Egbuonu AC, Obidoa O, Ezeokonkwo CA et al., (2009): Hepatotoxic effects of low dose oral administration of monosodium glutamate in male albino rats. African Journal of Biotechnology Vol. 8 (13), pp. 3031-3035.

Eweka AO, Igbigbi PS and Ucheya RE (2011): Histochemical Studies of the Effects of Monosodium Glutamate on the Liver of Adult Wistar Rats. Ann Med Health Sci Res Jan 2011; 1(1) 21-30
Freeman M (2006): "Reconsidering the effects of monosodium glutamate: a literature review". J Am. Acad. Nurse Pract. 18 (10): 482-6.

Geha R, Beiser A, Ren C et al., (1998): Multicenter multiphase double blind placebo controlled study to evaluate alleged reactions to monosodium glutamate (MSG). J. Allergy Clin. Immunol. 101:S243

Hahm E, Jin DH, Kang JS et al., (2007): The molecular mechanisms of vitamin $\mathrm{C}$ on cell cycle regulation in $\mathrm{B} 16 \mathrm{~F} 10$ murine melanoma. J. Cell Biochem. Nov., 1; 102(4):1002-10.

Hazar Y, Nayira A , Hala AA et al., (2008): Hepatoprotective Effect of $\mathrm{N}$-acetyl Cysteine and/or â-Carotene on Monosodium GlutamateInduced Toxicity in Rats . Research Journal of Medicine and Medical Sciences, 3(2): 206-215.

Heras A, Roach CM and Key ME (1995): Enhanced polymer detection system for immunohistochemistry. Lab., Invest., 72:165.

Higgins CM, Jung C and Ding H (2003): Mutant Cu, Zn supreoxide dismutase that causes motonuron degeneration is present in mitochondria in the CNC. J. Neuro. Sci., 22: 215.

Iwase M, Yamamoto M, Iino K et al., (1998): Obesity induced by neonatal monosodium glutamate treatment in spontaneously hypertensive rats : an animal model of multiple risk factors. Hypertens.Res., 43:62-68.

Kametaka AI, Takagi M, Hayakawa T et al., (2002): "Interaction of the chromatin compactioninducing domain (LR domain) of Ki-67 antigen with HP1 proteins". Genes Cells (England) 7 (12): 1231-42.

Kim JE, Jin DH, Lee SD et al., (2008): Vitamin C inhibits p53-induced replicative senescence through suppression of ROS production and $\mathrm{p} 38$ MAPK activity. Int. J. Mol. Med. Nov; 22(5):651-5.

Kondoh T and Torii K (2008): "MSG intake suppresses weight gain, fat deposition and plasma leptin levels in male Sprague-Dawley rats". Physiol. Behav. 95 (1-2): 135-44.

Leung A Y and Foster S (2003): "Monosodium Glutamate". Encyclopedia of Common Natural Ingredients: Used in Food, Drugs, and Cosmetics $.2^{\text {nd }}$ ed., New York: Wiley. pp. 373375.

Limaye PV, Raghuram N and Sivakami S (2003) : Antioxidants . Mol. cell Biochem. 243, 147-152.

Meves A, Stock SN and Beyerle A (2002): Vitamin C derivatives a scorbyl palmitate promotes ultraviolet B-induced peroxidation and cytotoxicity in kertinocytes. J. Invest. Dermatol., 119 (5): 1103-1108.

Ortiz GG , Bitzer-Quintero OK, Beas Zárate $\mathrm{C}$ et al., (2006): Monosodium glutamate-induced damage in liver and kidney:a morphological and 
biochemical approach Biomedicine \& Pharmacotherapy (60) PP ( 86-91)

Oscar OW, Ebenezer OF, Godwin OE et al., (2006): Effect of vitamine $\mathrm{E}$ on monosodium glutamate induced hepatotoxicity and oxidative stress in rats. Indian Journal of Biophysics (43) PP (2024).

Padayatty S J, Katz A, Wang Y et al., (2003): "Vitamin C as an antioxidant: evaluation of its role in disease prevention." Journal of the American College of Nutrition 22 (1): 18-35.

Pavlovic V, Pavlovic D, Kocic G et al., (2009): Ascorbic acid modulates monosodium glutamate induced cytotoxicity in rat thymus. Bratisl Lek Listy 110 (4) 205-209

Pincus MR and Abraham NZ (2006): Interpreting laboratory results. In: McPherson RA, Pincus MR, eds. Henry's Clinical Diagnosis and Management by Laboratory Methods. $21^{\text {st }}$ ed. Philadelphia, Pa: Saunders Elsevier; chap 8.

Rahmanzadeh R, Hüttmann G, Gerdes J et al., (2007):

"Chromophore-assisted light inactivation of
pKi-67 leads to inhibition of ribosomal RNA synthesis". Cell Prolif., 40 (3): 422-30.

Sakr S, Okdah A and El-Abed F (2003): Gibberellin A3 Induced Histological and Histochemical Alterations in the liver of Albino Rats,Sience Asia 29 : 327-331.

Scholzen T and Gerdes J (2000): The Ki-67 protein: from the known and the unknown. J Cell Physiol.; 182(3):311-322.

Sherlock S (1997): Assessment of liver function Disease of liver and biliary system: Sheila Sherlock, 10th ed., London; Blackwell science ltd; 17-32.

Stevenson D D (2000):"Monosodium glutamate and asthma". J. Nutr. 130: 1067S-1073S.

Sung An, Kang JH, Kim DH et al., (2011): Vitamin C increases the apoptosis via up-regulation p53 during cisplatin treatment in human colon cancer cells. BMB Rep., 44(3):211-6.

Willams A N and Woessner K M (2009):"Monosodium glutamate 'allergy': menace or myth?" Clinical \& Experimental Allergy 39: 640-646

Young IS and Woodside JV (2001): Antioxidants in health and disease. J. Clin. Pathol. 54(3):176-86.

\section{الملخص العربي}

\section{دراسة دور مضاد الأكسدة ( فيتامين ج). في معادلة بمية الاستخدام المزمن لجلوتاميد أحادي

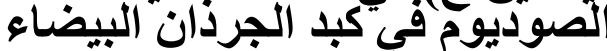

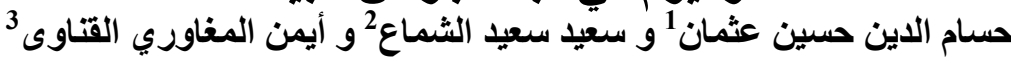

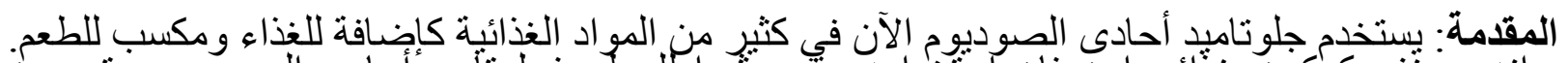

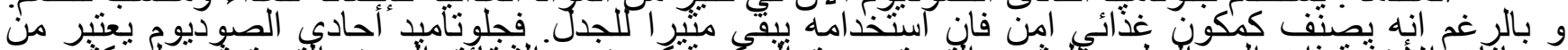

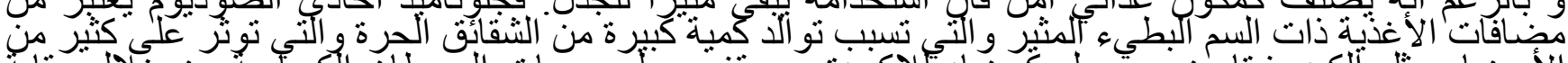

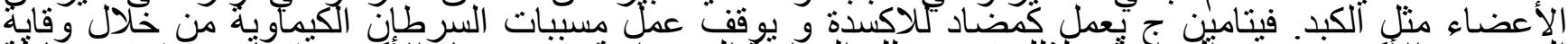

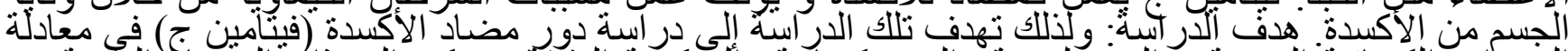

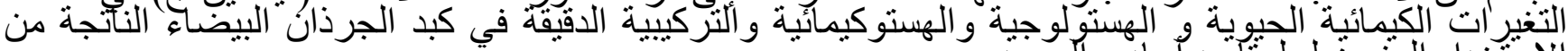

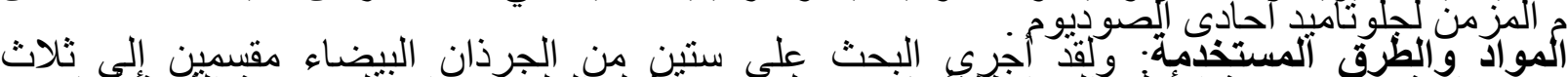

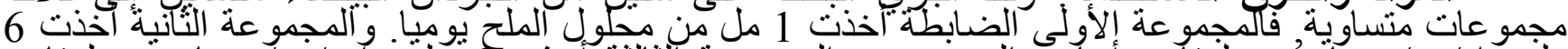

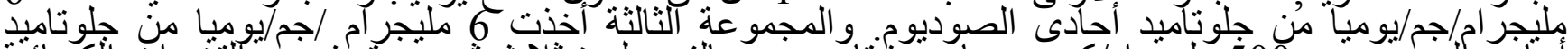

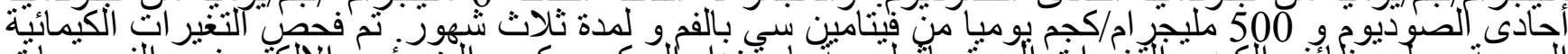

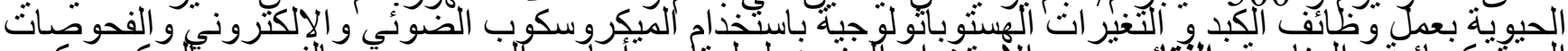

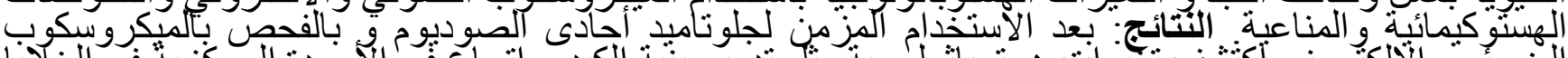

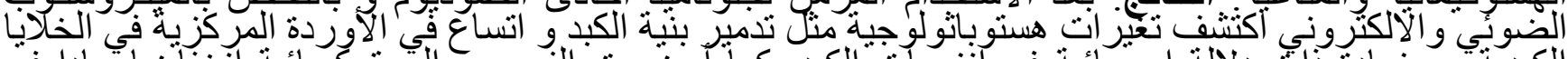

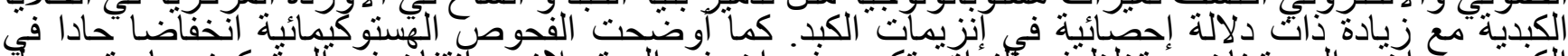

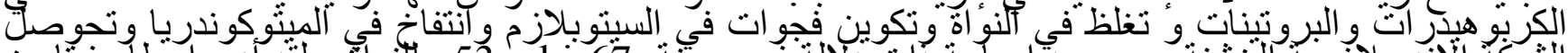

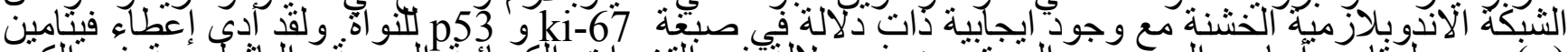

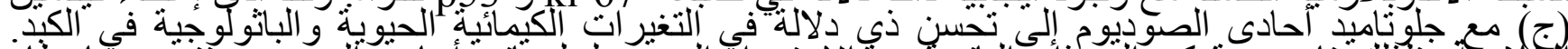

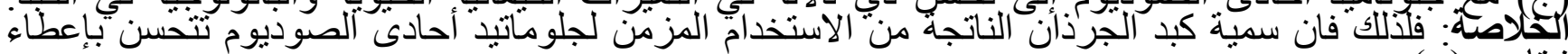

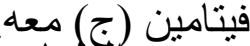
الهُمات أنمفتاحية: جلوماتيد أحادى الصوديوم فيتامين (ج) الكبد.

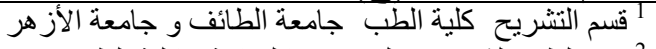

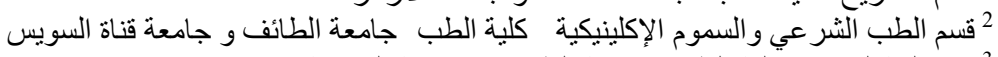

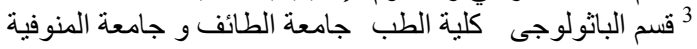

